stroke events, especially when they were making prescribing decisions for other patients they treated shortly thereafter. However, this would reduce the likelihood of finding a reduction in warfarin prescribing after an adverse bleeding event; our results may therefore underestimate the true effect of adverse experiences on warfarin prescribing.

Finally, our analysis of the impact of ischaemic stroke on warfarin prescribing may have been underpowered to detect small effects.

\section{Implications and conclusions}

Our findings provide further insight about reasons for underuse of warfarin in the treatment of atrial fibrillation and, more generally, about patterns of care for other similar conditions. As the prevalence of atrial fibrillation is increasing, ${ }^{10}$ and ischaemic strokes related to atrial fibrillation are a burden for patients and the healthcare system, efforts to address specific barriers to appropriate atrial fibrillation care are essential. Based on our results, these interventions should also address physicians' perceptions of risk associated with warfarin use.

\section{Contributors: See bmj.com.}

Funding: Harvard Pilgrim Health Care Foundation and a Canadian Institutes of Health Research in Chronic Disease New Emerging Theme (NET) programme grant (NET 54010). NKC was also supported by the Harvard Medical School fellowship in pharmaceutical policy research, a Frank Knox scholarship from Harvard University, and a Canadian Institutes of Health Research postdoctoral fellowship. SBS and DR-D are investigators in the HMO Research Network Center for Education and Research in Therapeutics, funded by the US Agency for Healthcare Research and Quality, and were also supported by grant No R01 AG022362-01 from the National Institute on Aging. AL is a senior scientist of the Canadian Institutes of Health Research. Competing interests: None declared.

Ethical approval: The ethics review board of Sunnybrook and Women's College Health Sciences Centre, Toronto, approved this study.

1 Hart RG, Benavente O, McBride R, Pearce LA. Antithrombotic therapy to prevent stroke in patients with atrial fibrillation: a meta-analysis. Ann Intern Med 1999;131:492-501.

\section{What is already known on this topic}

Warfarin is underprescribed to patients with atrial fibrillation

Physicians' overestimation of the risks of anticoagulation is a commonly cited explanation for the observed patterns of warfarin use

These perceptions may be influenced by physicians' experiences with warfarin use in their patients

\section{What this study adds}

Physicians are less likely to prescribe warfarin after one of their patients has a major adverse bleeding event associated with warfarin

A thromboembolic stroke in a patient with atrial fibrillation not on anticoagulation does not influence the odds that a physician will use warfarin in subsequent patients.

2 Fang MC, Stafford RS, Ruskin JN, Singer DE. National trends in antiarrhythmic and antithrombotic medication use in atrial fibrillation. Arch Intern Med 2004;164:55-60.

3 Cohen N, Almoznino-Sarafian D, Alon I, Gorelik O, Koopfer M, Chachashvily $\mathrm{S}$, et al. Warfarin for stroke prevention still underused in atrial fibrillation: patterns of omission. Stroke 2000;31:1217-22.

4 Majeed A, Moser K, Carroll K. Trends in the prevalence and management of atrial fibrillation in general practice in England and Wales, 1994-1998: analysis of data from the general practice research database. Heart 2001;86:284-8.

5 Bungard TJ, Ghali WA, Teo KK, McAlister FA, Tsuyuki RT. Why do patients with atrial fibrillation not receive warfarin? Arch Intern Med 2000;160:41-6.

6 Beyth RJ, Antani MR, Covinsky KE, Miller DG, Chren MM, Quinn LM, et al. Why isn't warfarin prescribed to patients with nonrheumatic atrial fibrillation? J Gen Intern Med 1996;11:721-8.

7 Raiford DS, Perez Gutthann S, Garcia Rodriguez LA. Positive predictive value of ICD-9 codes in the identification of cases of complicated peptic ulcer disease in the Saskatchewan hospital automated database. Epidemiology 1996;7:101-4.

8 Tirschwell DL, Longstreth WT Jr. Validating administrative data in stroke research. Stroke 2002;33:2465-70.

9 Kellen JC, Russell ML. Physician specialty is associated with differences in warfarin use for atrial fibrillation. Can J Cardiol 1998;14:365-8.

10 Go AS, Hylek EM, Phillips KA, Chang Y, Henault LE Selby JV, et al. Prevalence of diagnosed atrial fibrillation in adults: national implications for rhythm management and stroke prevention: the anticoagulation and risk factors in atrial fibrillation (ATRIA) study. JAMA 2001;285:2370-5. (Accepted 8 November 2005)

doi $10.1136 /$ bmj.38698.709572.55

\title{
bmjlearning.com
}

\section{How to put NICE guidelines into practice}

Producing guidelines can be a laborious job. They have to be evidence based, up to date, and reliable. To produce good ones you have to do a thorough literature search and get input from a range of interested parties, from patients to professors. And you have to do all this on the hoof-the public want guidelines on new drugs as soon as possible rather than in a year's time. It's a proud moment when you publish them, but that is when the real work begins-clinicians putting them into practice. Without this final step, the guidelines will gather dust and nothing will change.

So how best to put them into practice? One route is to provide education for those clinicians who have to implement them. In November 2005 NICE commissioned BMJ Learning to produce a series of learning modules based on its guidance. In this pilot project the modules cover NICE guidelines on how best to refer patients with suspected cancer of the lung, lower gastrointestinal tract, or breast. ${ }^{1}$ These modules are a series of interactive case histories. They enable you to assess your baseline knowledge of when and how urgently to refer patients with suspected cancer. You can then learn via case histories about best practice in this area. When you get to the end of the modules you should have thoroughly trained and tested your knowledge and skills. By learning actively rather than by just reading text, you should remember what you have learnt for much longer. ${ }^{23}$

However, you still have to put what you have learnt into practice, and to help you do this we have added an audit tool to BMJ Learning. Using this tool, you can assess how you cared for patients before doing the module and how you cared for them afterwards, and the main changes that completing the module has made to your practice. The modules are available on www.bmjlearning.com.

Kieran Walsh clinical editor, BMJ Learning

(bmjlearning@bmjgroup.com)

1 National Institute for Health and Clinical Excellence. Referral for suspected cancer. www.nice.org.uk/page.aspx?o = 261649 (accessed 12 Dec 2005).

2 Tobun A, Stanley C. Cognitive psychology on memory. www.scism.sbu.ac.uk/ inmandw/tutorials/memory/g3.htm (last updated 21 Jan 1998, accessed 12 Dec 2005).

3 Suresh K. Tips on:effective reading. BMJ 2002;324(suppl):7. (Career Focus http://careerfocus.bmijournals.com/cgi/content/full/324/7328/S7a) 